\title{
Stressful life events: association with physical and mental health conditions among older adults in Bhutan
}

\begin{abstract}
This cross-sectional study explored the prevalence of stressful life experiences (SLEs) and their relationship with health conditions among older adults in Bhutan. A face-to-face interview was completed at homes and community settings. A total of 337 people aged 60 to 101years were recruited from stapes, temples and local markets in four geographic regions. Measurements included checklists of Stressful Life Events (SLEs) and chronic health conditions, Kessler psychological distress scale (K10) and WHO-5 Wellbeing Index. Frequent back pain, memory decline, depression, mobility impairment, insomnia, and disease of the lungs were most common significantly different between the genders. Older adults in Bhutan had a complex variety of health conditions influenced by SLEs. Compared to participants with 1-5 SLEs, those with 8-14 SLEs had the higher odds of self-rating poor health by twofold ( $\mathrm{OR}=2.07 ; 95 \% \mathrm{CI}: 1.22-3.52)$. Comprehensive healthcare should address SLEs to mitigate their impact on health and improve overall quality of life and wellbeing of the person.
\end{abstract}

Keywords: stressful life events, health, older adults, Bhutan
Volume 6 Issue 5 - 2017

\author{
Nidup Dorji,' Michael Dunne ${ }^{2}$ \\ 'Department of Public Health, Khesar Gyalpo University of \\ Medical Sciences of Bhutan, Bhutan \\ ${ }^{2}$ School of Public Health and Social Work, Queensland \\ University of Technology, Australia
}

\begin{abstract}
Correspondence: Nidup Dorji, Department of Public Health, Faculty of Nursing and Public Health, Khesar Gyalpo University of Medical Sciences of Bhutan, Bhutan,
\end{abstract}

Email nidupdorji.dorji@gmail.com

Received: October 08, 2017 | Published: November 27, 2017

\section{Introduction}

Stress is a multidimensional and composite concept. ${ }^{1}$ It is a major part of life, beginning from the prenatal period until the end of life. ${ }^{2}$ Every individual experiences stressful events at some point in life. ${ }^{3}$ However, the experiences of stressful events differ more consistently on types by gender rather than the overall number of stressful events. ${ }^{4}$ The incidence of various life events also varies within social groups and from population to population. ${ }^{5}$ Exposure to chronic stressful events significantly increases the vulnerability to a wide variety of physical and mental health outcomes. ${ }^{6-8}$ SLEs involving death, suicide, or illness of a significant people including children, parents, or sibling may increase the risk of depression or anxiety., ${ }^{9}$ Life events and morbidity related to chronic conditions are the common stressors for older adults ${ }^{11}$ affecting both their physical and psychological health outcomes. ${ }^{12}$ The extent to which stress contributes to poor health outcome is often difficult to determine. However, the impacts of adversities on health vary depending on how a person views it as threat or challenge. ${ }^{13}$ SLEs therefore present major public health challenges. Till date, there is no evidence of systematic study on the prevalence of SLEs, and their influence on health outcomes among older adults in Bhutan. Therefore, this study was undertaken to determine the prevalence of SLEs and their probable influence on health outcomes. It is envisaged that findings from the study can serve as baseline information and inform programs and policies in investing for effective measures to reduce the impact of SLEs and promote health and wellbeing of older adults in Bhutan.

\section{Methodology}

\section{Research design}

This cross-sectional survey was designed to assess significant association between SLEs, self-reported general and specific health problems among older adults 60years and above in Bhutan. Data were collected between November 2014 to January 2015 by the principal researcher and trained research assistants (RAs).

\section{Study sites and sampling scheme}

Due to lack of prior information on SLEs and their impact on health outcomes among older adults in Bhutan, the calculation of the sample size was based on the number of variables. ${ }^{14}$ The scoring was done for the whole 20 items used to assess SLEs. However, the categorization of the cumulative SLEs was not based on any standards, but purely done to illustrate the distribution of scores to be near to normal. With an approximation of 25 variables included for this study, sample was determined at 337 which are statistically valid. The study population consisted of 189 males and 148 females, aged 60years and over, residing in the four major commercial towns of Bhutan(Thimphu, Phuntsholing, Gelephu, and Samdrup Jongkhar) at the time of data collection. Convenient sampling was applied for this study. The principal investigator and the RAs, contacted the participants mostly at the stupas, temples, pagodas, towns, and food markets within the study sites. These places are generally used by older adults in Bhutan for socialisation. Participants able to communicate in any of the four main languages (Dzongkha, English, Tshanglalo, and Lhotshamkha), and has no sign and symptoms of cognitive or hearing impairment or not admitted to any institutions were qualified for the study.

\section{Instrumentation}

We applied Stressful Life Events Checklist assessing 20 different SLEs, and a modified version of general health checklist to assess the status of physical and mental health conditions. We also applied established WHO-5 Wellbeing Index and Kessler's Psychological 
distress scale to measure emotional wellbeing and psychological distress. The instrument was pre-tested and showed satisfactory internal consistencies for general health conditions (Cronbach's alpha $=0.71)$, SLEs(Cronbach's alpha=0.89), WHO-5 wellbeing Index (Cronbach's alpha=0.96), and Kessler 10(Cronbach's alpha=0.85).

\section{Data collection and techniques}

Six final year nursing students (four males and two females) from the Faculty of Nursing and Public Health, Khesar Gyalpo University of Medical Sciences of Bhutan, were recruited and trained as RAs. All the RAs were well versed and fluent in all the four languages assigned for data collection. A three day workshop was conducted by the principal investigator to carefully orient and train RAs on the use of survey instrument and the aims and objectives of the study. At the time of data collection, every effort was made to ensure respondents feel safe and comfortable. The data collection process for each interview included brief session to explain the aims and objectives of the study, information to obtain consent, right to non-participation, and maintenance of anonymity. Face-to-face interview were conducted in the place of choice convenient to the participants after obtaining verbal and written consent from each respondents.

\section{Data analysis}

The collected data was entered and analysed using SPSS(Statistical Package for Social Sciences) version 21 for windows. Findings are expressed in percentage, mean and standard deviation. Bi variate analysis was conducted using chi-square tests, one-way ANOVA, univariate logistic regression, and bi variate correlation tests. For all statistical tests, a significance level of $\alpha=0.05$ was applied.

\section{Ethical consideration}

The Research Ethics Board of Health (Approval REBH/ approval/2011/013) of the Ministry of Health, Bhutan, granted permission to conduct the study.

\section{Results}

\section{Socio-demographic characteristics}

A total of 337 consisted of $189(56.1 \%)$ elderly males and $148(43.9 \%)$ elderly females. The mean age was 71.5 ranged between 60 to 101years. A slight more than half $179(53.1 \%)$ were married. Most of the participants were Buddhist 304(90.2\%). About $84.6 \%$ with almost all of the women $143(96.6 \%)$ had no formal education. Nearly half $154(46 \%)$ of the participants are currently employed (Table 1).

\section{Prevalence of SLEs}

As displayed in Table 2, death of a parent $327(97 \%)$ or child $230(68.2 \%)$, experience by a period of week or more unable to feed or cloth children $188(55.8 \%)$, loss of crops or animals $182(54 \%)$ or significant damage due to natural calamities $172(51 \%)$ severely impacting livelihood, children leaving household 167(49.6\%) were the common reported SLEs. About three quarters $(75 \%)$ of the SLEs experienced were more likely to be reported by females. Those experiences included death of spouse $81(54.7 \%)$ and children $118(79.7 \%)$, and parents $145(98.0 \%)$, increase in the number of arguments with spouse 70(47.3\%), children leaving home 75(50.7\%), damage of properties due to natural calamities $82(55.4 \%)$ or loss of crops impacting livelihood $86(58.1 \%)$, and a period of time unable to feed or clothe children $88(59.5 \%)$. Male participants reported higher experience of divorce/separation $26(13.8 \%)$, detention in the jail 5(2.6\%), prevented from being able to earn livelihood 91(48.1\%), and death or illnesses of close friends $79(41.8 \%)$. The difference in the experience of the death of a spouse $(p$-value $<0.05)$ or death of a child(p-value $<0.001)$ was found significant between the gender. Detention in the jail or other institution was the lowest recorded SLE $6(1.8 \%)$ in this study. The participants' experience of SLEs ranged from one to as high as 14 different SLEs. Nearly half 159(47.2\%) reported 8 and above types of SLEs in life.

Table I Socio-demographic characteristics of the sample

\begin{tabular}{|c|c|}
\hline Socio-demographic characteristics & $\mathbf{N}(\%)$ \\
\hline \multicolumn{2}{|l|}{ Age in Years } \\
\hline $60-69$ & |43(42.4) \\
\hline $70-79$ & 132(39.2) \\
\hline$\geq 80$ & $62(18.4)$ \\
\hline \multicolumn{2}{|l|}{ Gender } \\
\hline Male & $189(56.1)$ \\
\hline Female & |48(43.9) \\
\hline \multicolumn{2}{|l|}{ Marital status } \\
\hline Married & $179(53.1)$ \\
\hline Not married & $26(7.8)$ \\
\hline Widowed & $132(39.2)$ \\
\hline \multicolumn{2}{|l|}{ Religion } \\
\hline Buddhism & $304(90.2)$ \\
\hline Not Buddhist & $33(9.8)$ \\
\hline \multicolumn{2}{|l|}{ Education level } \\
\hline No formal schooling & $285(84.6)$ \\
\hline Some form of schooling & $52(15.4)$ \\
\hline \multicolumn{2}{|l|}{ Languages spoken } \\
\hline Speak at least one of four languages & $188(55.8)$ \\
\hline Speak at least two of four languages & $87(25.8)$ \\
\hline Speak three to all four languages & $62(18.4)$ \\
\hline \multicolumn{2}{|l|}{ Work Status in the last 12 months } \\
\hline Employed & $155(46.0)$ \\
\hline Home maker & $5 I(15.1)$ \\
\hline Unemployed & |31(38.9) \\
\hline
\end{tabular}

Note $n=$ Number of participants; $S D=S t a n d a r d$ deviation 
Table 2 Prevalence of stressful life events (item wise) by gender

\begin{tabular}{|c|c|c|c|c|}
\hline Individual and cumulative SLEs & Male $n(\%)$ & Female $n(\%)$ & Total n(\%) & p-value \\
\hline Death of a spouse? & $74(39.2)$ & $81(54.7)$ & $155(46.0)$ & $0.004^{*}$ \\
\hline Divorce or separation? & $26(13.8)$ & $16(10.8)$ & $42(12.5)$ & 0.416 \\
\hline Detention in jail or other institutions? & $5(2.6)$ & $\mathrm{I}(0.7)$ & $6(1.8)$ & $0.235 \dagger$ \\
\hline Death of a child? & $112(59.3)$ & $118(79.7)$ & $230(68.2)$ & $<0.001 * *$ \\
\hline Death of a parent? & $182(96.3)$ & $145(98.0)$ & $327(97.0)$ & $0.522 \dagger$ \\
\hline Major personal injury or illnesses? & $72(38.1)$ & $56(37.8)$ & $128(38.0)$ & 0.961 \\
\hline Being unable or prevented you from being able to earn livelihood? & $91(48.1)$ & $69(46.6)$ & $160(47.5)$ & 0.781 \\
\hline Major changes in the health or behaviour of a family member? & $40(21.2)$ & $36(24.3)$ & $76(22.6)$ & 0.491 \\
\hline Death or severe illness of a close friend? & $79(4 \mid .8)$ & $59(39.9)$ & I38(40.9) & 0.72 \\
\hline Major increase in the number of arguments with spouse? & $76(40.2)$ & $70(47.3)$ & $146(43.3)$ & 0.193 \\
\hline Son or daughter leaving household? & $92(48.7)$ & $75(50.7)$ & 167(49.6) & 0.716 \\
\hline Major conflict with family of spouse? & $21(\mid 1.1)$ & $22(14.9)$ & $43(12.8)$ & 0.305 \\
\hline $\begin{array}{l}\text { Significant damage due to natural calamities(landslides, earthquake, flood, } \\
\text { etc.)? }\end{array}$ & $90(47.6)$ & $82(55.4)$ & $\mid 72(5 \mid .0)$ & 0.156 \\
\hline Loss of crops or animals that has a severe impact on the livelihood? & $96(50.8)$ & $86(58.1)$ & $182(54.0)$ & 0.181 \\
\hline $\begin{array}{l}\text { Physical assault such as being attacked, hit, slapped, kicked, and beaten up by } \\
\text { family and non-family members? }\end{array}$ & $28(\mid 4.8)$ & $27(18.2)$ & $55(16.3)$ & 0.398 \\
\hline $\begin{array}{l}\text { Period of a week or more when so poor that couldn't properly feed and } \\
\text { clothe children? }\end{array}$ & $100(52.9)$ & $88(59.5)$ & I88(55.8) & 0.23 \\
\hline Period of time when couldn't afford to have children go to school? & $57(30.2)$ & $56(37.8)$ & $113(33.5)$ & 0.138 \\
\hline Theft or robbery of important possessions & $19(10.1)$ & $20(13.5)$ & $39(11.6)$ & 0.324 \\
\hline Worsening of relationships with children? & $19(10.1)$ & $20(13.5)$ & $39(\mid 1.6)$ & 0.324 \\
\hline Worsening of relationship with spouse? & $12(6.3)$ & II(7.4) & $23(6.8)$ & 0.696 \\
\hline Cumulative Distal SLEs & - & - & - & 0.252 \\
\hline 5 -Jan & $56(29.6)$ & $32(21.6)$ & $88(26.1)$ & \\
\hline 7-Jun & $48(25.4)$ & $42(28.4)$ & $90(26.7)$ & \\
\hline$\geq 8$ & $85(45.0)$ & $74(50.0)$ & $159(47.2)$ & \\
\hline
\end{tabular}

Note $n=$ Number of participants; ${ }^{*} \mathrm{p}$-value $<0.05 ; * *$-value $<0.00 \mathrm{I} ; \nmid \mathrm{p}$-value by fisher's exact test

Self-rated general health, specific health conditions, and medications

As shown in Table 3, slightly more than half 179(53.2\%) selfreported their general health to be good to excellent. However, about $207(61.4 \%)$ of the sample perceived deterioration in their general health conditions over the past year. Nearly half $148(45.8 \%)$ and $220(66.1 \%)$ self-reported experience of problems with walking and memory/concentration in the past four weeks, respectively. About
$266(78.9 \%)$ of the participants visited health care centres in the past year and mostly received treatment from the medical doctors $247(92.9 \%)$. About 221(66\%) reported being on medication over the past four weeks due to their health problems. Common health problems from highest to lowest were recorded for frequent back pain $226(67.1 \%)$, memory decline 204(61.4\%), depression $155(46.4 \%)$, mobility impairment 153(45.7\%), insomnia 142(42.4\%), and pulmonary diseases $123(36.9 \%)$. 
Table 3 Self-report general health, health seeking behaviour, and specific health problems

\begin{tabular}{|c|c|}
\hline General health and health seeking behaviour & $\mathrm{n}(\%)$ \\
\hline \multicolumn{2}{|l|}{ Self-report general health conditions } \\
\hline Poor-fair & 158(46.9) \\
\hline Good-excellent & $179(53.1)$ \\
\hline \multicolumn{2}{|c|}{ Compared to year ago, you say your Health Condition is: } \\
\hline Worse now & 207(6I.4) \\
\hline About the same & $109(32.3)$ \\
\hline Better now & $2 \mathrm{I}(6.2)$ \\
\hline \multicolumn{2}{|l|}{ Ability to walk in the last four weeks } \\
\hline No problem with walking & $175(54.2)$ \\
\hline Have problem with walking & $148(45.8)$ \\
\hline \multicolumn{2}{|l|}{ Problems with memory in the past four weeks } \\
\hline No problem with memory & $113(33.9)$ \\
\hline Have problem with memory & $220(66.1)$ \\
\hline \multicolumn{2}{|l|}{ Visited health worker in the past year } \\
\hline Yes & $266(78.9)$ \\
\hline No & $7 I(2 I . I)$ \\
\hline \multicolumn{2}{|l|}{ Visited different health care workers } \\
\hline Doctor & 247(92.9) \\
\hline Other health workers & $19(7.1)$ \\
\hline \multicolumn{2}{|l|}{ Specific health problems } \\
\hline Frequent back pain & $226(67.5)$ \\
\hline Memory decline & $204(6 I .4)$ \\
\hline Joint disease & $20 I(60.2)$ \\
\hline Arthritis & $197(60.1)$ \\
\hline Visual impairment & $191(57.4)$ \\
\hline High blood pressure & $135(52.7)$ \\
\hline Fatigue & $170(5 \mid .1)$ \\
\hline Depression & $155(46.4)$ \\
\hline Mobility impairment & $153(45.7)$ \\
\hline Insomnia & $142(42.4)$ \\
\hline Pulmonary disease & $123(36.9)$ \\
\hline Hearing problem & $85(25.5)$ \\
\hline Stomach ulcers & $71(23.0)$ \\
\hline Gout & $54(16.4)$ \\
\hline Musculoskeletal disorders & $46(13.8)$ \\
\hline Diabetes & $34(12.8)$ \\
\hline Skin problems & $26(7.8)$ \\
\hline Heart disease & $16(6.8)$ \\
\hline Liver problem & $12(5.3)$ \\
\hline Stroke & $6(2.2)$ \\
\hline Kidney disease & $6(2.4)$ \\
\hline Any type of cancer & $4(1.5)$ \\
\hline
\end{tabular}

Note $n=N u m b e r$ of participants; ${ }^{*} \mathrm{p}$-value $<0.05 ;{ }^{* *} \mathrm{p}$-value $<0.01$ 
Relationship between SLEs, health conditions, emotional wellbeing and psychological distress

Table 4 shows the prevalence and the relative odds of health problems by number of SLEs. Health conditions such as frequent back pain, pulmonary disease, diabetes, gout, joint disease, visual and hearing impairment, fatigue, mobility impairment, depression, insomnia, and memory decline are significantly associated with SLEs. When compared to participants with 1-5 SLEs, those with an experience of $\geq 8$ SLEs had the higher odds of reporting frequent back pain(OR=3.15, 95\%CI: 1.81-5.48), pulmonary disease(OR=5.15,
95\%CI: 2.69-9.87), $\operatorname{gout}(\mathrm{OR}=2.95, \quad 95 \% \mathrm{CI}: \quad 1.24-7.00)$, joint disease $(\mathrm{OR}=2.80, \quad 95 \% \mathrm{CI}: \quad 1.63-4.82)$, visual $(\mathrm{OR}=1.71,95 \% \mathrm{CI}$ : 1.00-2.91) and hearing impairment $(\mathrm{OR}=4.06,95 \% \mathrm{CI}: 1.94-8.47)$, fatigue $(\mathrm{OR}=2.28,95 \% \mathrm{CI}: 1.33-3.89)$, mobility impairment $(\mathrm{OR}=4.88$, 95\% CI: 2.73-8.71), depression( $\mathrm{OR}=5.54, \quad 95 \% \mathrm{CI}: \quad 3.07-9.98)$, insomnia(OR=3.63, 95\%CI: 2.05-6.42), or memory decline( $\mathrm{OR}=2.16$, 95\% CI: $1.25-3.74)$, and higher odds of self-rating poor health by almost twofold or more(OR=2.07; 95\%CI:1.22-3.52). Furthermore, significantly lower wellbeing score $(\mathrm{p}$-value $<0.01)$ and higher psychological distress (p-value $<0.001)$ was reported with higher cumulative SLEs (Table 5).

Table 4 Prevalence and adjusted relative odds of specific disease by SLEs

\begin{tabular}{|c|c|c|c|c|}
\hline \multirow{2}{*}{ Specific health problems } & \multirow{2}{*}{$\begin{array}{l}\text { Prevalence } \\
\text { (\%) OR (95\% Cl) }\end{array}$} & \multicolumn{3}{|c|}{ Number of stressful life events } \\
\hline & & $1-5(n=89)$ & $6-7(n=89)$ & $\geq 8(n=159)$ \\
\hline \multirow{2}{*}{ Back pain } & Prevalence (\%) & 19 & 27.9 & 53.1 \\
\hline & $\mathrm{OR}(95 \% \mathrm{Cl})$ & I.0(Ref.) & $2.48(I .33-4.6 I)^{*}$ & $3.15(1.81-5.48)^{* * *}$ \\
\hline \multirow{2}{*}{ Pulmonary disease } & Prevalence (\%) & 11.4 & 24.4 & 64.2 \\
\hline & $\mathrm{OR}(95 \% \mathrm{Cl})$ & I.0(Ref.) & $2.74(1.33-5.65)^{*}$ & $5.15(2.69-9.87)^{* * *}$ \\
\hline \multirow{2}{*}{ Heart disease } & Prevalence (\%) & 18.8 & 25 & 56.3 \\
\hline & $\mathrm{OR}(95 \% \mathrm{Cl})$ & I.0(Ref.) & I.36(0.29-6.33) & $1.64(0.43-6.30)$ \\
\hline \multirow{2}{*}{ High BP } & Prevalence (\%) & 23 & 20.7 & 56.3 \\
\hline & $\mathrm{OR}(95 \% \mathrm{Cl})$ & I.0(Ref.) & $0.75(0.37-\mid .52)$ & I.34(0.73-2.46) \\
\hline \multirow{2}{*}{ Stroke } & Prevalence (\%) & 16.7 & 33.3 & 50 \\
\hline & $\mathrm{OR}(95 \% \mathrm{Cl})$ & I.0(Ref.) & $2.00(0.18-22.54)$ & I.72(0.18-16.88) \\
\hline \multirow{2}{*}{ Diabetes } & Prevalence (\%) & 26.5 & 5.9 & 67.6 \\
\hline & $\mathrm{OR}(95 \% \mathrm{Cl})$ & I.0(Ref.) & $0.19(0.04-0.91)$ & I.3I (0.57-3.03) \\
\hline \multirow{2}{*}{ Gout } & Prevalence (\%) & 13 & 27.8 & 59.3 \\
\hline & OR(95\%Cl) & I.0(Ref.) & $2.4 I(0.93-6.26)$ & $2.95(1.24-7.00)^{*}$ \\
\hline \multirow{2}{*}{ Joint disease } & Prevalence (\%) & 19.9 & 24.4 & 55.7 \\
\hline & OR(95\%Cl) & I.0(Ref.) & $1.48(0.81-2.68)$ & $2.80(1.63-4.82)^{* * *}$ \\
\hline \multirow{2}{*}{ Visual impairment } & Prevalence (\%) & 23 & 23.6 & 53.4 \\
\hline & $\mathrm{OR}(95 \% \mathrm{Cl})$ & I.0(Ref.) & $1.00(0.55-|.8|)$ & $1.7 I(1.00-2.91)^{*}$ \\
\hline \multirow{2}{*}{ Hearing impairment } & Prevalence (\%) & 11.8 & 23.5 & 64.7 \\
\hline & OR(95\%Cl) & I.0(Ref.) & $2.20(0.96-5.03)$ & $4.06(1.94-8.47)^{* * *}$ \\
\hline \multirow{2}{*}{ Stomach ulcers } & Prevalence (\%) & 19.7 & 28.2 & 52.1 \\
\hline & $\mathrm{OR}(95 \% \mathrm{Cl})$ & I.0(Ref.) & $\mathrm{I} .4 \mathrm{I}(0.65-3.03)$ & I.50(0.75-2.99) \\
\hline \multirow{2}{*}{ Liver disease/Hepatitis } & Prevalence (\%) & 33.3 & 33.3 & 33.3 \\
\hline & $\mathrm{OR}(95 \% \mathrm{Cl})$ & I.0(Ref.) & $1.04(0.25-4.34)$ & $0.57(0.14-2.38)$ \\
\hline \multirow{2}{*}{ Skin problems } & Prevalence (\%) & 19.2 & 34.6 & 46.2 \\
\hline & $\mathrm{OR}(95 \% \mathrm{Cl})$ & I.0(Ref.) & I.85(0.59-5.75) & I.34(0.46-3.93) \\
\hline \multirow{2}{*}{ Fatigue } & Prevalence (\%) & 20.6 & 23.5 & 55.9 \\
\hline & $\mathrm{OR}(95 \% \mathrm{Cl})$ & I.0(Ref.) & $|.2|(0.67-2.21)$ & $2.28(1.33-3.89)^{* *}$ \\
\hline \multirow{2}{*}{ Mobility impairment } & Prevalence (\%) & 14.4 & 20.9 & 64.7 \\
\hline & OR( $(95 \% \mathrm{Cl})$ & I.0(Ref.) & $1.66(0.87-3.17)$ & $4.88(2.73-8.7 \mathrm{I})^{* * *}$ \\
\hline \multirow{2}{*}{ Musculoskeletal } & Prevalence (\%) & 23.9 & 21.7 & 54.3 \\
\hline & $\mathrm{OR}(95 \% \mathrm{Cl})$ & I.0(Ref.) & $0.85(0.34-2.12)$ & I.26(0.59-2.69) \\
\hline
\end{tabular}




\begin{tabular}{|c|c|c|c|c|}
\hline \multirow{2}{*}{ Specific health problems } & \multirow{2}{*}{$\begin{array}{l}\text { Prevalence } \\
\text { (\%) OR }(95 \% \mathrm{Cl})\end{array}$} & \multicolumn{3}{|c|}{ Number of stressful life events } \\
\hline & & $1-5(n=89)$ & $6-7(n=89)$ & $\geq 8(n=159)$ \\
\hline \multirow{2}{*}{ Depression } & Prevalence (\%) & 13.5 & 20.6 & 65.8 \\
\hline & $\mathrm{OR}(95 \% \mathrm{Cl})$ & I.0(Ref.) & $1.74(0.90-3.35)$ & $5.54(3.07-9.98)^{* * * *}$ \\
\hline \multirow{2}{*}{ Insomnia } & Prevalence (\%) & 16.2 & 20.4 & 63.4 \\
\hline & $\mathrm{OR}(95 \% \mathrm{Cl})$ & I.O(Ref.) & $1.35(0.70-2.58)$ & $3.63(2.05-6.42)^{* * *}$ \\
\hline \multirow{2}{*}{ Memory decline } & Prevalence (\%) & 22.1 & 23 & 54.9 \\
\hline & $\mathrm{OR}(95 \% \mathrm{Cl})$ & I.0(Ref.) & $1.00(0.55-1.80)$ & $2.16(1.25-3.74)^{* *}$ \\
\hline \multirow{2}{*}{ Poor health } & Prevalence (\%) & 18.4 & 22.8 & 58.9 \\
\hline & OR(95\%Cl) & I.0(Ref.) & $2.92(1.69-5.02)^{* * * *}$ & $2.07(1.22-3.52)^{* *}$ \\
\hline
\end{tabular}

Note $n=$ Number of participants; ${ }^{*} \mathrm{p}$-value $<0.05$; **p-value $<0.0$ I; ***p-value $<0.00$ I; BP=blood pressure;

$\mathrm{OR}=$ odds ratio

Table 5 Relationship between wellbeing, psychological distress, and SLEs

\begin{tabular}{llll} 
& \multicolumn{3}{l}{ Number of stressful life events } \\
\cline { 2 - 4 } Wellbeing and psychological distress & $\mathbf{I - 5}(\mathbf{n}=\mathbf{8 9})$ & $\mathbf{6 - 7}(\mathbf{n}=\mathbf{8 9})$ & $\geq \mathbf{8}(\mathbf{n}=1 \mathbf{5 9})$ \\
\hline Wellbeing $(M \pm S D)$ & $15.4 \pm 4.77$ & $15.2 \pm 4.25$ & $13.5 \pm 4.50 * *$ \\
KIO(M $\pm S D)$ & $15.1 \pm 6.30$ & $14.4 \pm 4.27$ & $17.5 \pm 5.73 * * *$ \\
\hline
\end{tabular}

$\mathrm{M} \pm \mathrm{SD}=$ Mean \pm Standard Deviation; ${ }^{*} \mathrm{p}$-value $<0.00 \mathrm{I}$

\section{Discussion}

This is a survey of 337 elderly people from four geographic locations of Bhutan aimed to describe the prevalence of SLEs and demonstrate how these experiences may be related to older adults' self-rated general health and their health conditions. Health problems such as frequent back pain, memory decline, visual impairment, disease of the joints, fatigue, depression, insomnia, elevated blood pressure reported were consistent with findings from earlier researches. ${ }^{15,16}$ Such complaints indicate healthcare providers to be mindful of the need to adopt comprehensive approach while delivering health services to older adults. Almost all the participants have experienced at least one form of SLEs in their lifetime. Except for the experience of death of spouse and children significantly reported higher among female in this study, the experience of cumulative SLEs did not differ by gender. However experience of SLEs among gender differed by types consistent with the review of Hatch. ${ }^{4}$ Individuals who experienced higher cumulative SLEs had higher odds of reporting specific health problems such as frequent back pain, diseases of lungs, joint, and gout; vidual and hearing impairment, fatigue, depression, insomnia, and memory decline by more than two folds. These findings were consistent with the previous studies where strong association was shown between severe stressful events with poor physical functioning, higher risk of disabilities, and poor mental health. ${ }^{6-17}$ Likewise, as observed in the past study, ${ }^{18,19}$ a significant positive relationship was also found between cumulative SLEs and psychological distress in this study. Evidence also suggests psychological correlates lead to increase of physical health complaints. ${ }^{19}$ As majority of the participants reported being Buddhist in this study, teachings on the significance of compassion, impermanence, and the acceptance of reality such as death highly talked in the Buddhist world can help alleviate the negative influence of SLEs and promote desirable health outcomes. Furthermore, intervention such as mindfulness-based therapy may be implemented.

\section{Conclusion and implications}

Aside from death of parents and children, period of week or more unable to feed or clothe children, loss of crops or domestic animals, and significant damage on properties due to natural calamities were common reported SLEs. SLEs had significant positive relationship with both physical and mental negative health outcomes. This study has some limitations. Non-probability sampling technique was adopted for this study and therefore the findings cannot be generalized to the true population. While evidence suggests exposure to certain extent of stress are necessary for the survival of species as its exposure provides opportunity to develop toughness or experiences of control and mastery beneficial throughout life, such association was not examined in this study. A high proportion of respondents with no formal education may have compromised accurate self-report of their health conditions. Moreover, this study did not include clinical measurement of health status and was not able to gain access to medical records to verify self-report. This study has its own strength as well. This study was one of the first of its kind to investigate the prevalence of SLEs, common physical and mental health disorders and their significant association using systematic and scientific based approach. Findings suggest the need for further exploration of SLEs which may be different among the generations. This study also provides baseline information on which the future studies on similar topics could be compared. Findings strongly recommend the need for prevention and interventions to alleviate negative influence of SLEs on health and promote wellbeing and quality of life of a person. 


\section{Acknowledgements}

The authors would like to thank all the participants and the data collectors of this study.

\section{Declaration of conflict of interest}

The authors declare no potential conflicts of interest with respect to the research, authorship, and publication of this article.

\section{References}

1. Le Moal M. Historical approach and evolution of the stress concept: a personal account. Psychoneuroendocrinology. 2007;32(Suppl 1):S3-S9.

2. Lupien SJ, Mc Ewen BS, Gunnar MR, et al. Effects of stress throughout the lifespan on the brain, behaviour and cognition. Nat Rev Neurosci. $2009 ; 10(6): 434-445$.

3. Wu G, Feder A, Cohen $\mathrm{H}$, et al. Understanding resilience. Front Behav Neurosci. 2013;7:10.

4. Hatch SL, Dohrenwend BP. Distribution of traumatic and other stressful life events by race/ethnicity, gender, SES and age: a review of the research. Am J Community Psychol. 2007;40(3-4):313-332.

5. Cleary PJ. A checklist for life event research. J Psychosom Res. 1980;24(3-4):199-207.

6. Toussaint L, Shields GS, Dorn G, et al. Effects of lifetime stress exposure on mental and physical health in young adulthood: How stress degrades and forgiveness protects health. J Health Psychol. 2016;21(6):1004-1014.

7. Donoghue HM, Traviss-Turner GD, House AO, et al. Life adversity in depressed and non-depressed older adults: A cross-sectional comparison of the brief LTE-Q questionnaire and life events and difficulties interview as part of the CASPER study. J Affect Disord. 2016;193:31-38.

8. Miller GE, Chen E, Zhou ES. If it goes up, must it come down? Chronic stress and the hypothalamic-pituitary-adrenocortical axis in humans. Psychol Bull. 2007;133(1):25-45.
9. Kessing LV, Agerbo E, Mortensen PB. Does the impact of major stressful life events on the risk of developing depression change throughout life? Psychol Med. 2003;33(7):1177-1184.

10. DeBeurs E, Beekman A, Geerlings S, et al. On becoming depressed or anxious in late life: similar vulnerability factors but different effects of stressful life events. British J Psychiatry. 2001;179:426-431.

11. Hsu HC. Impact of Morbidity and Life Events on Successful Aging. Asia Pac J Public Health. 2011;23(4):458-469.

12. Sherina MS, Rampal L, Mustaqim A. Factors Associated with Chronic Illness among the Elderly in a Rural Community in Malaysia. Asia Pac J Public Health. 2004;16(2):109-114.

13. Klages U, Weber AG, Wehrbein H. Approximal plaque and gingival sulcus bleeding in routine dental care patients: relations to life stress, somatization and depression. J Clin Periodontol. 2005;32(6):575-582.

14. Green SB. How Many Subjects Does It Take To Do A Regression Analysis. Multivariate Behav Res. 1991;26(3):499-510.

15. Borglin G, Jakobsson U, Edberg AK, et al. Self-reported health complaints and their prediction of overall and health-related quality of life among elderly people. Int J Nurs Stud. 2005;42(2):147-158.

16. Marventano S, Ayala A, Gonzalez N, et al. Multimorbidity and functional status in community-dwelling older adults. Eur J Intern Med. 2014;25(7):610-616.

17. Leserman J, Whetten K, Lowe K, et al. How Trauma, Recent Stressful Events, and PTSD Affect Functional Health Status and Health Utilization in HIV-Infected Patients in the South. Psychosom Med. 2005;67(3):500-507.

18. Lim ML, Lim D, Gwee X, et al. Resilience, stressful life events, and depressive symptomatology among older Chinese adults. Aging Ment Health. 2015;19(11):1005-1014.

19. Schwarzer R, Schulz U. Stressful Life Events, in Handbook of Psychology. USA: John Wiley \& Sons, Inc; 2003. 